\title{
Language and Culture Research in the Context of International Education and Second Language Acquisition
}

\author{
Sheri Zhang, University of Ottawa \\ Robert Anthony, University of Victoria
}

\begin{abstract}
This article is about research methods employed in the context of international education and second language acquisition. Researchers have attempted to interpret communication problems occurring between native and non-native speakers of English within a broad cultural and educational context. Such cultural studies addressing pragmatic and sociocultural dimensions often include methodology debates. We clarify the characteristics and the appropriate use of quantitative-based research methods and qualitative methods of naturalistic inquiry on speech acts, to encourage further research projects on culture based on either method.
\end{abstract}

\begin{abstract}
Résumé
Cet article traite des méthodes de recherche utilisées dans le contexte de l'éducation internationale et de l'acquisition d'une langue seconde. Les chercheurs ont essayé d'interpréter les problèmes de communication qui se produisent entre les personnes dont la langue maternelle est l'anglais et ceux avec une autre langue maternelle dans un contexte libéral de culture et de l'éducation. De telles études qui abordent les dimensions pragmatiques et socioculturelles, embrassent aussi les débats sur la méthodologie. Nous voudrions éclaircir ici les caractéristiques et l'emploi approprié des méthodes de recherche à base quantitative sur l'action du parler et les méthodes de recherche qualitative naturaliste dans le but d'encourager des projets de recherche futurs sur la culture, basés sur l'une ou l'autre de ces méthodes.
\end{abstract}

\section{Introduction}

This paper is about language and culture and their relationship in communicative situations which may lead to miscommunication and misunderstandings in crosscultural interaction and interchanges. We particularly address the methodologies employed to examine culture issues in the area of language teaching and learning, for analyzing and understanding the phenomena involved in such communicative interchanges from the view of the educational anthropologist. That is, interlocutors are regarded as actors following rules of which they are not consciously aware. In other words, cultural beliefs are either consciously or unconsciously forming presuppositions that are not shared by communicators from different cultures (Zhang, 2002), and the absence of the common denominator of a shared cultural background may lead to misunderstanding at the 
sociocultural level because of the absence of "an exact cultural counterpart" (Spindler, 1997).

Cross-cultural communication is central in successful communication, yet cultural issues and concepts have not been sufficiently examined in second language acquisition research. In comparison to other fields like anthropology and cultural studies, there has been little serious discussion of the concept of culture in the Teaching of English to Speakers of Other Languages (TESOL) over the last two decades (Atkinson, 1999). Further, there are disagreements, debates and discussions among researchers regarding the types of methodology for cultural studies in second language acquisition (Johnson, 1992; Davis, 1995; Lazaraton, 1995, 2000, 2003).

The debate over the source of cross cultural communication difficulties is confounded by methodological divergences. Interactions between Canadian and international students are often encumbered by communication problems even when the non-native speaker (NNS) has high levels of fluency in English and/or French. Students of Asian cultural background often do not get their message across in an effective and acceptable manner even though they have a high TOEFL score and were accepted by a Canadian university. According to researchers such as House (1997), cross-cultural pragmatic failure may occur because of mother-tongue and native (Canadian) culture interference. Acting on what is pragmatically acceptable in their native culture, such as in China, Japan and Korea, NNSs may misinterpret the intentions of Canadian English/French native speakers or speak in ways that are culturally unacceptable.

Researchers in the area of second language acquisition (SLA), language education and cross-cultural communication have attempted to interpret communication problems of speakers with non English linguistic and cultural backgrounds in a broad cultural and educational context. In order to explain communication problems between native and non-native speakers and their communication breakdowns, "investigators must go beyond an analysis of the purely linguistic features of the interaction (phonology, morphology, syntax, and prosody), and consider as well its pragmatic and sociocultural dimensions" Gass \& Varonis (1991, p. 121). Cultural studies in the area of SLA often result in the discussion of research methodologies to be employed - the quantitative based speech act research and qualitative methods of naturalistic inquiry.

The methodologies for examining cross-cultural miscommunication since the 1970s include the approaches introduced by cultural anthropologists such as Keesing (1976) along with the newly emerging discipline "Language and Culture Studies" (Shaul \& Furbee, 1998) which have resulted in an increasing use of research methodologies that look beyond the structural linguistic level, aiming instead at the underlying cultural suppositions of the speakers and listeners. These new approaches have their roots in anthropology, ethnography, and philosophy, and can be subsumed under the qualitative paradigm of "research that seeks to discern meaning" (Tesch, 1990), using the descriptive/interpretive approach of phenomenology and hermeneutics - the main ingredients in any qualitative research. 
Generally speaking, miscommunication can be viewed from two different perspectives: either the quantitative sociolinguistic, or the qualitative ethnographic. For the sociolinguist or functionalist, "unit of analysis" for studying interaction includes "discourse phases", "discourse strategies", "gambits", and "speech acts" (House, 1997). In contrast, the ethnographic researcher analyzes "stories", or "data narratives" (Tesch, 1990). Each of the two approaches has its own merits, and implies different methods of data collection analysis, for different research purposes. In Lazaraton's (1995) view, the former relates to language acquisition, the latter to language socialization.

Qualitative research can contribute to our understanding of language acquisition and use. While the 1960s and 1970s saw a high tide of large-scale quantitative studies, nowadays social scientists have returned to stressing the importance of individual action. This trend has influenced SLA research and gave rise to a great deal of debate, misunderstanding, and confusion about the use of qualitative research methods in applied linguistics (Davis, 1995). The debate on qualitative and quantitative methodologies in second language acquisition became especially heated in the 1990s when the naturalists claimed that quantitative scientific methodologies are often inappropriate in SLA because of the subjective nature of human subjects. The rationalists (traditionalists) countered by criticizing the naturalists of advocating a non-scientific philosophy of research that lacks validity. As Larsen-Freeman \& Long (1991) put it: "For some researchers the distinction between the two represents more than a preference between two types of methodologies; rather it represents a fundamental clash between two paradigms” (p. 11).

Again, the debate in SLA is similar to the research debate occurring in the humanities and social sciences. The methodology debate in SLA has continued to enrich the research in this area (Lazaraton, 2000, 2003). This article draws from the research work in this area and contributes to research in comparative education and cultural studies in the context of SLA through highlighting the differences between qualitative and quantitative methods.

With qualitative methods becoming increasingly accepted in recent years, students who write theses on cultural studies relating to comparative education and second language acquisition often ask questions about the choice of research methodology when they design their research projects. The most frequently discussed questions are as follows:

- What means are available to the researcher to analyze cross-cultural interchanges and to establish possible links underlying (unconscious) cultural belief systems and discourse behaviour in different contexts;

- What are the characteristics of various methodologies such as interlanguage pragmatics, ethnography of communication; and

- What units of analysis have been used to conduct this type of research, and what are their strong and weak points?

The present article gives an overview of the methodology discussion in comparative education in the context of SLA with a flashback to its hottest debate in the middle 1990s. The article summarizes the importance of linking language 
and culture of international students' interchanges with Canadians in real-world settings. After describing the commonly used research methodologies and data types in this area, we examine the appropriateness of quantitative and qualitative research approaches, and finally elucidate the strong and weak points of the sociolinguistic and ethnographic approaches.

\section{Analyzing Native-nonnative Interchanges: Language and Culture}

"It is impossible to study sociocultural phenomena such as languages from a completely objective view. [...] Language used by meaning-creating humans is potentially symbolic interaction in which people can (re)interpret each other and the language(s) they use" (Shaul \& Furbee, 1998; p. 187).

SLA researchers are trying to answer the question why international students with high TOFEL scores often fail to respond in a way acceptable to their Canadian counterparts. As the first of several different, possibly interacting sources of the problem, House (1993) emphasizes inadequate perception, specifically "inappropriate comprehension at the syntactic, semantic, pragmatic and discourse levels of language..." (p. 161). Gass \& Selinker (1994) point out that language learners must learn more than just the pronunciation, the lexical items, the appropriate word order, but must also learn the appropriate way to use those words and sentences in that second language.

Most of the sociolinguistic work has been conducted within the framework of "speech acts" (House, 1982; 1986; 1993). Speech acts are certain functions of language, such as complaining, thanking, apologizing, refusing, requesting, inviting. Speech act theory represents a more intricate kind of language analysis, which is conducted by sociolinguists for research linking language and culture, rather than only focusing on linguistic forms. Studies on speech acts have demonstrated the difficulties language learners experience. Beebe and Takahashi (1989) report on how Japanese and English native speakers differ in their statement of disagreements, and in giving embarrassing information. Blum-Kulka, House and Kasper (1989) point out the difficulties that even advanced second language learners have in encoding requests and apologies.

Traditionally, SLA is mainly related with the three disciplines of linguistics, psychology, and sociolinguistics. Of course, there are other areas that relate to SLA, such as sociology, anthropology, communication, philosophy etc; however, they are usually downgraded to "potential contributors to an understanding of the nature of second language acquisition [...] given that at present they have had less of an impact on the field of SLA" (Gass \& Selinker, 1994, p. 188). Many mainstream SLA researchers prefer the conventional research methodologies over the qualitative methods that have their roots in sociology, anthropology and philosophy.

Other SLA theorists such as Johnson (1992), Davis (1992, 1995), and Lazaraton (1995) maintain that ethnographic/qualitative research has gained a strong foothold in Second Language Research, and advocate the qualitative paradigm. Ethnographic researchers believe that ethnographic/qualitative data can provide rich insight into human behaviour. Davis (1995) points out that linguistic 
anthropologists, ethnographers of communication, and other qualitative researchers interested in language issues have offered an alternative to mainstream SLA studies. They define language as human behavior which, as stated by Guba and Lincoln (1994) "...unlike that of physical objects, cannot be understood without reference to the meanings and purposes attached by human actors to their activities" (p. 106). The qualitative paradigm includes the research methodologies suitable for examining language and culture, especially the difficulties international students and Canadians have in understanding each other. Difficulties in cross-cultural communication are not only experienced by language learners, but also by Canadians who stay in foreign countries, such as in China. Qualitative research methods can also contribute to an inquiry that examines in what way westerners feel isolated or depressed while staying in China, and why Chinese-Canadians often feel non-Canadian.

Most speech act research is conducted based on linguistic categories, such as discourse and syntax analysis (Schmidt \& Richards, 1985). The use of "units of analysis", and the choice of data gathering and data analysis methods place speech act research within the quantitative paradigm. The dichotomy of the quantitative and qualitative research paradigms is reflected in the debate among SLA researchers. SLA methodologists such as Lazaraton (1995) do not believe that a consensus on the value of qualitative research among SLA researchers is possible. Viewed in terms of the two competing paradigms, research on the stories of Canadians in China or Chinese international students in Canada is not confined within the area of speech acts. Addressing language as a social behaviour embedded in the real world, such research requires a qualitative approach. An example of this type of research in SLA is Peirce's (1993) study on immigrant women. The qualitative approach expands the options for examining and understanding the sociocultural roots of communication phenomena.

SLA research on language socialization issues is characterized by the dichotomy of the quantitative approach mainly in the area of sociolinguistics, and the qualitative approach of ethnographic study. A typical quantitative study is based on an experimental design to test a hypothesis through the use of objective instruments; the researcher here is excluded as the instrument, and appropriate statistical analyses are carried out (Larsen-Freeman \& Long, 1991). For example, House (1986) in her speech act research uses "mean directness ratings", "mean politeness ratings" and other statistical constructs to express research results.

The qualitative approach is also known as "naturalistic inquiry", or "ethnography" (Tesch, 1990), or "phenomenology". The advantage of a phenomenological empirical study is that it provides an understanding of the real world, through the participants' lived experience (Tesch, 1990).

\section{Sociolinguistics and the Nature of Speech Act Research}

Traditionally, the social and cultural aspects have been overshadowed by the mental processes in SLA that usually do not have a sociological orientation (Davis, 1995; Johnson, 1992; Lazaraton, 1995). Applied linguists have generally recognized the contributions of sociolinguistic studies, but still sociolinguistics 
has commonly played a separate or complementary role in SLA. However, in conducting research, sociolinguists as mainstream researchers in SLA have drawn on the dominant methods of psychology collecting data through experimental techniques or surveys, and analyzing data using statistical methods. In examining speech acts phenomena which are viewed as having social origins, sociolinguists also have tended to assume that native speakers possess a set of social rules in their minds; these social rules can then be discovered and taught to language learners (Davis, 1995). Researchers have used a form of survey methodology to collect empirical data on speech acts and functions elicitation techniques such as role play and completion tasks. Some have examined compliments and compliment exchanges (Manes \& Wolfson, 1981; Holmes, 1988; Wolfson, 1989). Other researchers have concentrated on the two speech acts "Requests" and "Apologies" (House, 1982), or the speech act of "Requests" (House, 1986). Experimental designs and statistical data analyses have been used to identify the use of social rules by native and nonnative speakers (Kasper \& Dahl, 1991).

Generally, these studies are in the form of frequency counts, percentages and statistical “mean”. For example, Manes and Wolfson (1981) found the semantic composition of the compliments was highly regular. The most commonly occurring adjectives were "nice”, "good”, "beautiful”, "pretty" and "great". Recently, SLA researchers have developed research methodology on speech acts (Cohen \& Olshtain, 1994) emphasizing the "role-play interview" as a research method, to find a way of combining different approaches to describe a single speech act among native and nonnative speakers of a language.

\section{Ethnographic/Qualitative Methodologies}

The prototypical qualitative methodology is an ethnographic study in which the researchers derive and describe findings that promote greater understanding of how and why people behave the way they do. Qualitative researchers believe that human behavior is too complex to explain or predict based solely on statistics or theoretical considerations. For example, in her qualitative language-related ethnographic study, Peirce (1993) successfully focuses on SLA in terms of the societal and cultural factors that affect the learners, despite certain weaknesses pointed out by other SLA researchers such as Price (1997). Peirce (1993) shows how power is embedded in the social relations in which the immigrant women are engaged.

Hymes (1972) is a pioneer of ethnography of communication. The research paradigm of ethnography of communication, developed during the 1970's within the field of Applied Linguistics, focuses on the social meaning of language within the context of particular groups or cultures. Although ethnography of communication has often been included within the domain of sociolinguistics, researchers in ethnographic methods have tended to work and publish outside of the SLA and ESL fields in areas such as education, anthropology, and the sociology of language. The use of associated ethnographic methods in language related study has resulted in a split between ethnographic researchers and mainstream SLA researchers. Linguistic anthropologists such as Ochs \& 
Schieffelin (1984) and Scollon \& Scollon (1981) conducted ethnographic studies of child socialization into language within diverse cultural settings.

Following Ferguson \& Gumperz (1959), Hymes (1972) urges linguists and anthropologists to work toward a large and important area of human communication: "In order to develop models, or theories, of the interaction of language and social life, there must be adequate descriptions of that interaction, and such descriptions call for an approach that partly links, but partly cuts across, partly builds between the ordinary practices of the disciplines" (p.41). Fasold (1990) is one of the contemporary linguists to follow Hymes' call. In his definition, the approach to the sociolinguistics of language which relates to social and cultural values is called the ethnography of communication. The goal of ethnographic "Language and Culture" research is to explain the meaning of language in human life. Although research on speech acts and ethnography of communication are both under the umbrella of sociolinguistics, they differ both in research orientation and methodology.

\section{Methodologies and Units of Analysis}

Linguistically oriented methodologies define linguistic units of analysis: the word, the sentence, a discourse, a speech act etc. However, for a qualitative research design the term "unit of analysis" itself seems out of place, because it suggests a quantitative approach. If one accepted the term to describe the analytical process of a qualitative study, then the unit of analysis would have to be defined phenomenologically, as the participants' lived experience, or hermeneutically, as an instance of human behaviour. Or, in Tesch's (1990) terms, we deal with "description of events", or "stories".

Lesser Units of Human Language Use" and Discourse Behaviour Sociolinguistic research in SLA concentrates on, or restricts itself, to the "lesser units of human language use": questions of "implicature, deixis, anaphora and reference, and speech acts (Mey, 1993).

Such research abounds with technical terms, and is referred to as “micropragmatics". Van Dijk's (1977) view represents an important historical step towards widening our outlook on human language production, by recognizing the insufficiency of describing language as consisting of small, isolated units of description. He urges the researchers to transcend these by looking at larger units. We must extend our vision to the entirety of circumstances (not only linguistic) that surround the production of language. By widening our perspective to what surrounds spoken or written utterances, researchers also obtain a better understanding of what the utterances are really about. Mey (1993) uses the term "macropragmatics" to describe research that deals with larger units of analysis.

Regarding "discourse behaviour" as a reflection of cultural belief systems, in Mey's (1993) view, discourse analysis simply means "old-fashioned", grammar-and speech act-oriented analysis of spoken language. In the framework of discourse analysis, the concepts of rule, well-formedness, and so on have their natural place. One could say that discourse analysis is another simple extension of the "text grammar", as being the proper way of doing an extended linguistic 
analysis (p. 194). As to the methods used in discourse analysis, these are similar to those of classical, syntax-oriented grammar: one singles out a few, short sentences as examples, and builds one's theories on, or around, these isolated sentence tokens.

One of the most comprehensive empirical studies of speech act behaviour was the Cross-Cultural Speech Act Research Project (Blum-Kulka, House \& Kasper, 1989) in which a number of German-English contrastive pragmatic analyses were conducted, using a combination of elicited data. The data were triangulated with retrospective interviews and tests in which subjects were asked to assess the appropriateness of certain utterances in a given situation, or assess the level of politeness or directness in a set of utterances. House (1982) analyzed speech acts with 200 German and 100 English subjects, and basically confirmed the results of her work in the previous project: German speakers tend to opt for more direct realizations of requests, and they prefer to surround their requests with more content-oriented discourse strategies than the English native speakers who tend to prefer "interpersonally active and routinized" strategies.

In hindsight, speech act research does not appear to adequately address the phenomenon of miscommunication due to different (or missing) cultural suppositions in real life settings. Rather it examines how the same speech act is differently expressed in different languages. Furthermore, Johnson (1992) classifies speech act research as the "sociolinguistic study of language use" under "survey research", which examines one or more "variables" for larger numbers of entities. By contrast, ethnographic inquiry deals with the conceptual incongruities between different cultures that affect communication. In Fasold's (1990) understanding, "presuppositions are propositions that have to be true in order for some sentence or utterance to be meaningful, or perhaps appropriate. ... all presuppositions are related to context, in the sense that they depend on what people know or believe about the world" (p. 177).

In the context of ethnographic research projects, the term "cultural presupposition" (in contrast to the limited scope of "speech act") extends to the wide scope of culture as viewed by Ratner (1997). Culture is more than shared concepts about the meaning of things. Culture also consists of the way people raise children, educate the populace, produce goods and services, make and enforce social policies. Culture also includes the distribution of rights, privileges, opportunities, obligations, and wealth among various groups of people.

\section{The Larger Unit Called "Story"}

In the SLA field, qualitative research is alternatively known as naturalistic and interpretive. The long hermeneutic tradition in philosophy provides much of the theoretical basis for most qualitative research that is done from an interpretive perspective. Interpretation is a central concept in hermeneutics and has influenced the general approach of qualitative researchers. Hermeneutic theorists claim that there is no objective reality, and therefore no possibility of developing correct knowledge about reality. Instead, we develop interpretations of the world. Phenomenological description combined with hermeneutic interpretation makes 
up the qualitative researcher's "story", or "narrative” (Tesch, 1990). The researcher's key concepts of argument are grounded in the "story" rather than imposed on it by the investigator's perspective or someone else's theory. Similarly, Peirce (1993) uses larger units of ethnographic and sociocultural phenomena when she studies the ordinary "life-world": she is interested in the way the immigrant women experience their world, what it is like for them, and how to best understand them. In this case, the world view of the participants poses as a comprehensive "unit of analysis", and participant constructs are used to structure the research.

\section{Strong and Weak Points of the Different Approaches}

Both sociolinguistic and ethnographic research has contributed to the cultural perspective of language acquisition and language socialization in different ways. The differences mainly exist in research design. Sociolinguists use experimental techniques or surveys and analyze data using statistical methods. Ethnographic researchers within their naturalistic inquiry use strictly qualitative methods of data gathering and analysis.

\section{Speech Act Research in SLA}

Strong points: Research on speech acts represents a more intricate kind of language analysis. It is a sociolinguistic approach of studying language and relates to communicative competence instead of linguistic competence. Thus it can broaden the scope of second language learning inquiry and provide second language teaching with theoretical guidelines for designing a communicative syllabus (Schmidt \& Richards, 1985).

Weak points: Speech act research is too linguistically oriented. House (1993) defines three sources for "pragmatic failures", (1) Language-based difficulties, (2) inappropriate or inadequately expressed speech acts, (3) Non-partner-oriented responses.

\section{The Interpretive Qualitative Paradigm}

Strong points: This approach reveals the participants' “emic” view (the insider's view) to the researcher. The interpretive qualitative concept of "thick description" involves the "emic" perspective which includes the actors' interpretations and other sociocultural information. Ethnographic interpretive-qualitative inquiries allow the researcher to examine the social and/or sociocultural context of language learning and use, and to emphasize context and culture within Language and Culture Studies (Lazaraton, 1995). The ethnographic interpretive-qualitative approach could expand the restricted study of speech acts, such as House's (1982, 1986, 1993), beyond syntax and semantics. It could lead to a more complete linguistics concerned with how cultural presuppositions shape the non-native speaker's use of language in real life activities and social settings. This approach could help implement Hymes' call to develop an ethnographic model for the study of communication, leading to a more complete understanding of communication 
in multicultural settings (Saville-Troike, 1989). The ethnographic research approach allows researchers, like Peirce (1993), to conduct inquiries within a social and cultural setting; it further makes the research "data-driven", instead of "rule"- or "grammar-driven".

Weak points: There are questions regarding the validity and generalizability of results from ethnographic/qualitative research (Larsen-Freeman \& Long, 1991). On the other hand, Lazaraton (1995) argues that quantification of any set of data does not ensure generalizability to other contexts, nor does a large sample size, and suggests that qualitative research results are as generalizable as quantitative results. Qualitative inquiry is criticized for its "deconstructionism" (Gall, Borg \& Gall, 1996), as it does not follow any pre-structured, pre-determined grids or procedures. However, this "weak point" can also be viewed as a strong point in Tesch's (1990) sense, when she states that conducting scientific investigations is not a matter of following recipes.

\section{Conclusion}

For examining different or missing cultural suppositions that lead to miscommunication between native and non-native speakers of a language, researchers use either speech acts research or naturalistic inquiry to deal with culture differences and cultural suppositions, in the broader ethnographic meaning of Spindler (1997) as cultural background knowledge. Sociolinguistic study of speech acts has paved the way towards a better understanding of the use of language in SLA, however, the record of speech act theory as a help towards understanding and analysing real language use has not always been impressive (Mey, 1993).

Speech act research investigates mainly the linguistic encoding of certain ritualized utterances that might vary from culture to culture, but does not address issues relating to the different cultural backgrounds of the social actors involved in cross-cultural communication. Speech act research is usually restricted to linguistic activities dealing with cross-cultural communication in simulated settings, and is therefore narrower and more restricted in scope than the ethnographic approach that examines communication in real-world settings.

Spindler \& Spindler's (1997) discussion of "the cultural process and ethnography" is mainly concerned with ethnography of education and schooling, and educational anthropology. "If anthropology does not contribute a crosscultural perspective, then what does it contribute?" (p. 62). Rather than studying speech acts using experimental, quasi-experimental or survey methods for examining intercultural miscommunication phenomena, the strategy of using ethnographic data in education is of practical value. For conducting comparative international education research projects, we can draw from Spindler's (1997) discussion of "Transcultural Sensitization", and the recurring anthropological concept of an exact "cultural counterpart" or corresponding cultural concept. 
Among a variety of sociolinguistic approaches, the ethnographic research design that complies with the paradigm of interpretive qualitative research is becoming more acceptable. Data are gathered through qualitative methods such as interviews and observation, and other data such as questionnaire or content analysis can be added for triangulation. In such an inquiry, researchers attempt to synthesize a phenomenology of intercultural miscommunication in form of a "story", with all its anthropological, ethnographic and philosophical connotations.

\section{References}

Atkinson, D. (1999). TESOL and Culture. TESOL Quarterly, vol. 33, No. 4, 625-654.

Beebe, L. M. \& Takahashi, T. (1989). Sociolinguistic variation in face-threatening speech acts. Chastisement and disagreement. In M. R. Eisenstein (Ed.), The dynamic interlanguage: Empirical studies in second language variation (pp. 199-218). New York: Plenum.

Blum-Kulka, S., House, J. \& Kasper, G. (Eds.). (1989) Cross-Cultural Pragmatics: requests and apologies. Norwood, N.J.: Ablex.

Cohen, A. D. \& Olshtain, E. (1994). Researching the production of second-language speech acts. In Tarone, E. E., Gass, S. M. \& Cohen, A. D. (eds.). In Research methodology in second-language acquisition. Hillsdale, NJ: Erlbaum.

Davis, K. A. (1992). Validity and reliability in qualitative research on second language acquisition and teaching. TESOL Quarterly, vol. 26, 605-608.

Davis, K. A. (1995). Qualitative theory and methods in Applied Linguistics research. TESOL Quarterly, vol. 29, 427-453.

Fasold, R .(ed) (1990). The Sociolinguistics of Language. Cambridge, MA: Blackwell.

Ferguson, C. A. \& Gumperz, J. J. (1959). Linguistic diversity in south Asia: Studies in Regional, and Functional Variation. RCAFL P13; International Journal of American Linguistics 26 (3), pt. III.

Gall, M. D., Borg, W. R., \& Gall, J. P. (1996). Educational Research. An Introduction. White Plains, N.Y.: Longman.

Gass, S. M. and Selinker, L. (1994). Second language acquisition. An introductory course. Hillsdale, N.J.: Lawrence Erlbaum.

Gass, S. M. \& Varonis, E. M. (1991). Miscommunication in Non-native Speaker Discourse. In Coupland, N., Giles, H. \& Wiemann, J.M. (eds.), Miscommunication and problematic talk. Newbury Park, CA: Sage.

Guba, E. G. \& Lincoln, Y. S. (1989). Fourth generation evaluation. Newbury Park, CA: Sage.

Guba, E. G. \& Lincoln, Y. S. (1994). Competing Paradigms in Qualitative Research. In N. K. Denzin \& Y. Lincoln (Eds.), In Handbook of qualitative research (pp. 105117). Newbury Park, CA: Sage.

Holmes, H. (1988). Paying compliments: A sex-preferential politeness strategy. Journal of Pragmatics, 12, 445-465. 
House, J. (1982). "Oh excuse me please ...": apologizing in a foreign language. In: B. Kettemann et al. (Eds.), Englisch als Zweitsprache. Tübingen: Narr.

House-Edmondson, J. (1986). Cross-cultural Pragmatics and Foreign Language Teaching. In Probleme und Perspektiven der Sprachlehrforschung. Frankfurt/M.: Scriptor.

House, J. (1993). Toward a model for the analysis of inappropriate responses in native / nonnative interactions. In Interlanguage Pragmatics, pp. 161-183. New York and Oxford: Oxford University Press.

House, J. (1997). Translation Quality Assessment. A Model Revisited. Tübingen: Narr.

Hymes, D. (1972). Editorial introduction to "Language in society". Language in Society 1 (1).

Johnson, D. M. (1992). Approaches to research in second language learning. New York \& London: Longman.

Kasper, G., \& Dahl, M. (1991). Research methods in interlanguage pragmatics. Studies in Second Language Acquisition, 13, 215-147.

Keesing, R. M. (1976). Cultural Anthropology. A Contemporary Perspective. New York: Holt, Rinehart \& Winston.

Larsen-Freeman, D., \& Long, M. H. (1991). Second language acquisition research methodology. In An Introduction to Second Language Acquisition Research. London: Longman.

Lazaraton, A. (1995). Qualitative Research in Applied Linguistics: A Progress Report. TESOL Quarterly, vol. 29, 455-472.

Lazaraton, A. (2000). Current trends in research methodology and statistics in applied linguistics. TESOL Quarterly, vol. 34, 175-181.

Lazaraton, A. (2003). Evaluative criteria for qualitative research in applied linguistics: Whose criteria and whose research? Modern Language Journal 87, 1-12.

Manes, J., \& Wolfson, N. (1981). The compliment formula. In F. Coulmas (Ed.), Conversational routine (pp. 115 - 132). The Hague: Mouton.

Mey, J. L. (1993). Pragmatics. An Introduction. Oxford, U.K.: Blackwell.

Ochs, E., \& Schieffelin, B. B. (1984). Language acquisition and socialization: Three developmental stories and their implications. In R. A. Shweder \& R. A. LeVine (Eds.), Culture theory: Essays on mind, self and emotion (pp. 276-320). Cambridge: Cambridge University Press.

Peirce, B. (1993). Language learning, social identity, and immigrant women. Doctoral dissertation. Faculty of Education, University of Toronto.

Price, S. (1997). Comments on Bonny Norton Peirce's "Social Identity, Investment, and Language Learning". A reader reacts .... TESOL Quarterly, vol. 31, 331-337.

Ratner, Carl (1997). Cultural psychology and qualitative methodology. Theoretical and empirical considerations. New York and London: Plenum.

Saville-Troike, M. (1989). The ethnography of communication: An introduction. $2^{\text {nd }}$ ed. Oxford: Basil Blackwell.

Schmidt, R. W. \& Richards, J. C. (1985). Speech acts and second language learning. In J. C. Richards (Ed.). In The context of language teaching (pp. 100-128). Cambridge: Cambridge University Press.

Scollon, R., \& Scollon, S. (1981). Narrative, literacy and face in interethnic communication. Norwood, N.J.: Ablex.

Shaul, D. L., \& Furbee, N. L. (1998). Language and Culture. Prospect Heights, IL: Waveland.

Spindler, G. D. (1997). Transcultural Sensitization. In Education and Cultural Process. Prospect Heights, IL: Waveland. 
Spindler, G., \& Spindler, L. (1997). Cultural Process and Ethnography. An Anthropological Perspective. In Education and Cultural Process. Prospect Heights, IL: Waveland.

Tesch, R. (1990). Qualitative Research: Analysis Types and Software Tools. Basingstoke, U.K.: The Falmer Press.

Van Dijk, T. A. (1977). Text and context. London: Longman.

Wolfson, N. (1989). Perspectives: Sociolinguistics and TESOL. New York: Harper \& Row/Newbury House.

Zhang, S. (2002). Cultural Communication and Miscommunication: Chinese MBA Students in a Canadian Academic and Sociocultural Context. Doctoral dissertation. Faculty of Education, University of Ottawa.

Sheri Zhang teaches Chinese language and culture at the department of Modern Languages and Literatures at the University of Ottawa, Canada. Her research interests are in the areas of international education, second language acquisition, cross-cultural studies, and include the study of East Asian culture in the Canadian larger social context.

Robert Anthony is chair and professor at the Department of Curriculum and Instruction at the University of Victoria, Canada. His research areas cover analysis of text structure development in ESL learners, and classroom assessment of literacy. 